\title{
An Updated Procedure for Cecal Cannulation in Sheep and Cattle
}

\author{
J.S. CATON, L.J. KRYSL, A.S. FREEMAN, J.L. RUTTLE AND M.E. BRANINE
}

\begin{abstract}
Fifteen cattle (236-500 kg) and 38 sheep $(36-55 \mathrm{~kg})$ were fitted with 2 types of indwelling cecal cannulae. Cannulae were made of either clear silicone or plastic tubing. The surgery was conducted in ane-step procedure that involved pharmaceuticals and equipment that were readily available. Results indicated a success rate of $67 \%$ (33\% failure due to inability to locate the cecum at the time of surgery) in cattle and $100 \%$ in sheep. Both cannula types tested were acceptable, but the cannula made from plastic tubing was more desirable because it was less bulky, more durable, and easier to construct. Animals fitted with cecal cannulae appeared to be healthy and to have normal life spans.
\end{abstract}

Key Words: cecal cannulation, cattle, sheep

Procedures for cecal cannulation were described more than $\mathbf{3 0}$ years ago by Dougherty (1955). Phaneuf (1957) later used these techniques in early experiments on digestive physiology of sheep. More recently several researchers have reviewed hind gut digestive physiology (Ulyatt et al. 1975, Hoover 1978, and Stevens et al. 1980). Unfortunately, the publication of cecal cannulation procedures has not kept pace with the increase in research on hindgut digestion. DeGregorio et al. (1982) reported using an indwelling T-type cannula in the cecum of sheep; however, their procedure was only briefly outlined. Ralston et al. (1983) outlined a procedure for cecal cannulation in ponies. While the procedure may be adequate for ponies, it is difficult to adapt to sheep and cattle. The majority of researchers using cecal cannulae

J.L. Ruttle is professor, and other authors are graduate research assistants, Dept. of Animal and Range Sciences, New Mexico State University, Las Cruces 88003.

This article is New Mexico Agr. Exp. Sta. Journal No. 1230.

The authors would like to express their gratitude to Dr. F.C. Hinds, University of Wyoming, and S.J. Barron (DVM), Oklahoma State University, for their timely advice and consultation.

Manuscript accepted 8 December 1986. have failed to cite a cannulation procedure or only give a brief outline of their procedure. This paper provides a detailed description of cecal cannulation procedure that is suitable for both sheep and cattle.

\section{Materials and Methods}

\section{Cannula Types}

Two types of cannulae were used in sheep and cattle. The first type is a modification of the silicone cannula described by Ralston et al. (1983). Its construction consisted of clear silicone caulk ${ }^{1}$ poured onto a T-type mold and shaped with a putty knife dipped in 95\% ethanol. Once shaped, the cannula was allowed to dry and assembled as shown in Figure 1. Cannulae used for sheep and cattle were $17-\mathrm{mm}$ I.D. and $31-\mathrm{mm}$ I.D., respectively.

The second type of cannula was made from clear plastic tubing ${ }^{2}$ of varying diameters which depended on the size and species of the animal involved. For sheep we used 19.0-mm I.D. and $29.0-\mathrm{mm}$ I.D. in cattle. Inside flanges were made by splitting and tacking the tubing flat to a board. To ensure the inside flanges maintained their shape, tacked tubing was heated for $30 \mathrm{~min}$ in a $100^{\circ} \mathrm{C}$ forced-air oven. After cooling, a hole $2 \mathrm{~mm}$ smaller than desired cannula barrel was cut into the center of the inside flange. Cannula barrels, $15 \mathrm{~cm}$ long, were cut from tubing of the appropriate inside diameter. Both the flange and barrel were soaked in cyclohexanone for 10 to $20 \mathrm{~min}$. The barrel was then inserted into the pre-cut hole in the flange and rotated to ensure good contact. The whole unit was then placed in enough cyclohexanone to cover the joint and allowed to set for 10 to $15 \mathrm{~min}$. Finally, each cannula was air dried for $72 \mathrm{~h}$ before being fitted with an outside flange as shown in Figure 2. 'Clear silicone rubber sealent, Ace Hardware Corporation, Oaks Brook, Illinois
60521 .

2Plastic tubing, Kirkhill, inc., Downey, CA 90241. 


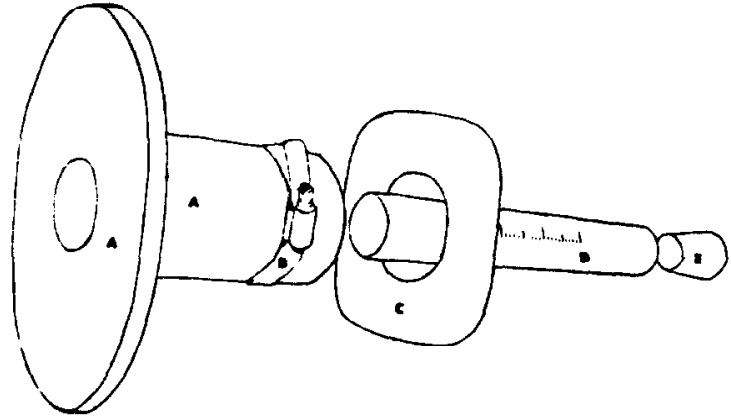

Fig. 1. Molded silicone cannula consisting of inside flange and barrel (A), hose clamp (B), outside flange (C), modified syringe barrel $(D)$, rubber stopper $(E)$.

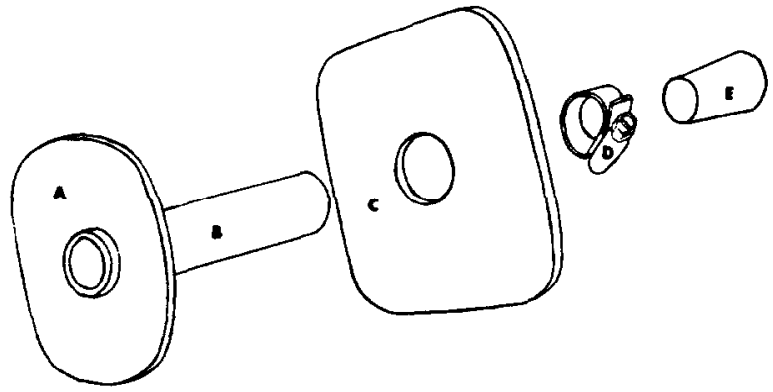

Fig. 2. Inside flange (A), cannula barrel (B), outside flange $(C)$, hose clampe (D), rubber stopper (E).

Outside flanges were constructed from food container lids, but could be made from almost any type of plastic material.

\section{Surgical Procedure}

Over a 3-month period, 15 cattle $(236-500 \mathrm{~kg})$ and 38 sheep (36-55 kg) ranging from 6 to 36 months of age were selected for cecal cannulation. These animals were fasted for $24 \mathrm{~h}$ and withheld from water $12 \mathrm{~h}$ before surgery.

Sheep were placed on an operating table in left lateral recumbency, exposing the right side for surgery. All 4 legs and the head were restrained to prevent injury to either the sheep or the surgical team (Fig. 3). In cattle, surgery was performed using either

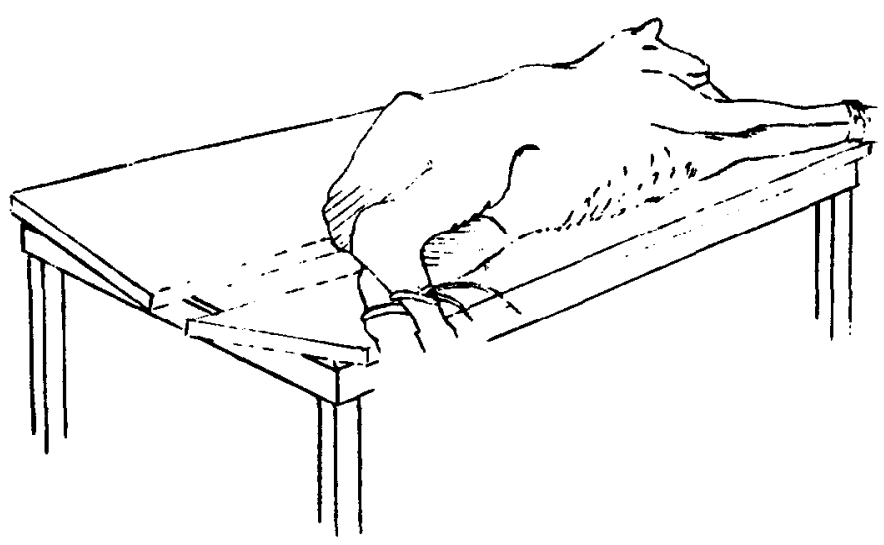

Fig. 3. Sheep positioned on surgical table.

a surgery table or a catch chute fitted with a standard headgate.

Surgical anesthesia consisted of a regimen that minimized st ress and pain. In most cecal cannulations, an intravenous injection of

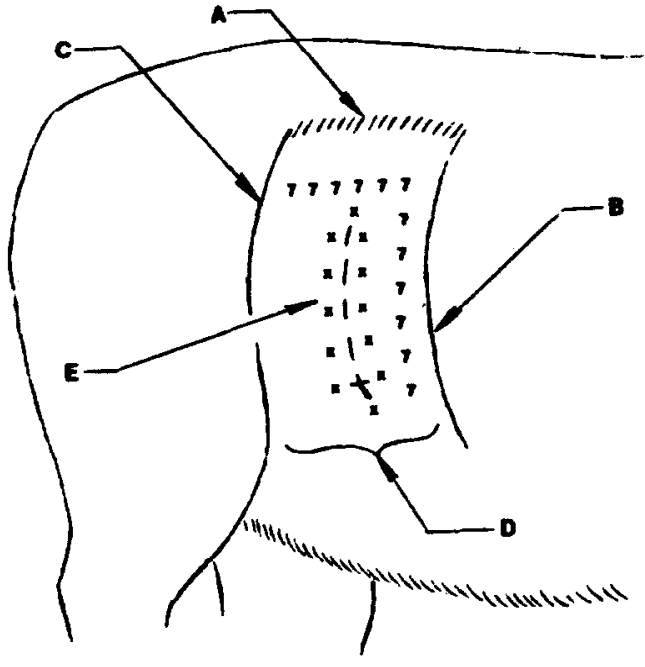

Fig. 4. Transverse processes ( $A)$, last rib $(B)$, tuber coxae $(C)$, surgical field $(D)$, incision site (E), injection sites for line or " $L$ " block $(X$ and 7 , respectively).

Sparine (promazine hydrochloride) ${ }^{3}$ was used as a general tranquilizer. Injections were given in the midrange dose of .66 to .77 $\mathrm{mg} / \mathrm{kg}$ body $\mathrm{wt}$ if the animal was on a surgical table and the lower range dose of .44 to $.55 \mathrm{mg} / \mathrm{kg}$ body wt if the animal was standing.

After adequate animal restraint, the surgical field (right paralumbar fossa and flank area) was located and, using Phisohex ${ }^{4}$ as a surgical scrub and and Zephiran ${ }^{4}$ as a disinfectant, the area was prepared for surgery by standard preparation procedures. The incision site was located and anesthesized with $1 \%$ Xylocaine (Lidocaine hydrochloride plus 1:100,000 added epinephrine) using either a line or an inverted "L" block (Fig. 4). The inverted " $L$ " block appeared to be more effective in desensitizing the area and is preferred to the line block. After administration of the local anesthetic, the surgical area was again flooded with Zephiran.

A 10.0 to $15.0-\mathrm{cm}$ incision beginning approximately $5 \mathrm{~cm}$ ventral to the lumbar processes was made dorsoventrally through the skin underlying fascia and fat layers. Muscle layers were separated by blunt dissection whenever possible. After the peritoneum was exposed, between 0.5 and $1.5 \mathrm{cc}$ of $1 \%$ Xylocaine was applied to the peritoneal surface to enhance anesthesia. The peritoneum was incised vertically with a scalpel and the incision lengthened with scissors. After the cecum was located and exteriorized, an incision just long enough to insert the cannula was made in the least vascular region farthest removed from the cecal artery. The incision was positioned 7.5 to $14.0 \mathrm{~cm}$ from the cecal apex, depending on the cecal size. After cannula insertion, the incision was closed with " 0 ", " 00 " or " 000 " chromic gut using a Connell suture pattern described by Frank (1964). A purse-string suture of chromic gut was also placed around the cannula barrel to prevent leakage. When the cecum was exteriorized, the organ was periodically irrigated with sterile physiological saline to prevent adhesions. After returning the cecum to the abdominal cavity, the cannula was placed in the ventral apex of the incision site. The surrounding peritoneum and muscle layers were closed with " 0 " chromic gut, using a simple continuous suture pattern. After the peritoneum and muscle layers were sutured, $10 \mathrm{cc}$ of Tri-sulfa ${ }^{6}$ was irrigated between the various muscle layers. The skin was sutured with nonabsorbable synthetic suture material (2/0 Braunamid) ${ }^{7}$ in an interrupted pattern. Tri-sulfa was also irrigated between the skin sutures and and the incision surface was treated with a $3 \%$ solution

3 Wyeth Laboratories, Inc., Philadelphia, Pennsylvannia 19101.

- . . . , srk, New York 10016

'Anchor Laboratories, Inc., St. Joseph, Mo.

'B. Braun Melsungen AG, W. Germany. Importer: Jorgensen Laboratories, Inc. Loveland, Colo. 80537. 
of iodine and a topical antibiotic (Furall) ${ }^{8}$. The outside flange was then affixed to the cannula. Antibiotic (Combiotic) ${ }^{9}$ was administered by intramuscular injection and the animal was housed in a recovery area.

\section{Post-operative Care}

Combiotic (procaine penicillin $G$ and dehydrostreptomycin sulfate) injections were given to both sheep ( 8 to $10 \mathrm{cc}$ ) and cattle ( 15 to $20 \mathrm{cc}$ ) every $24 \mathrm{~h}$ for 3 days after surgery, and discontinued if the animal was progressing satisfactorily. If further treatment was needed, only procaine penicillin $\mathrm{G}^{9}$ was administered. Animals were maintained on a good quality alfalfa hay, including salt and minerals, and given fresh water daily throughout recovery. Incision sites were inspected once or twice daily and topical antibiotic and pesticide were applied as needed. Animals were usually ready for experimental studies 4 to 6 weeks following surgery.

\section{Discussion and Conclusion}

Currently, 15 cattle and 38 sheep have been cannulated with a success rate of $67 \%$ in cattle and $100 \%$ in sheep. The reduced success rate associated with cattle was attributed to the fact that many of the steers carried excess finish, which made locating the cecum extremely difficult. We were unable to locate the cecum at the time of surgery in 5 of the steers, thus, we had a lower percentage of successful cecal cannulations in cattle than in sheep. Cattle weighing between 130 and $230 \mathrm{~kg}$ can be cannulated with little difficulty. Some variation in ease of sampling was observed and attributed to cannula position. Sampling was improved (cecal contents flowed much easier) if the cannula was located away from the blind end of the cecum, and postioned slightly more ventral than dorsal in the abdominal wall.

Both cannula types were acceptable for use in research. Modifications can be made in either cannula type by cutting the barrel and flanges to the desired length and shapes. In general, the plastic tubing cannula was preferable because it was less bulky, more durable and easier to construct, With both cannula types it was desirable to use outside flanges. These flanges prevented the cannula from being drawn into the cecum, which could result in the cannula becoming lodged in the large intestine with little chance of passage or removal.

\footnotetext{
BFarnam Companies, Omaha, Nebraska 68112
}

'Agriculture Division, Phizer Inc., New York, New York 10017.
This surgical procedure is simple and provides animals of good health and acceptable quality for experimental purposes. Several successful experiments have been conducted using animals fitted with cecal cannulae by this procedure (Caton et al. 1985, 1986a, b; Krysl et al 1986). Life expectancy of animals cannulated in this fashion is assumed to be near normal.

\section{Literature Cited}

Caton, J.S., A.S. Freeman, and M.L. Galyean. 1986a. The influence of protein supplementation on rumen and cecal fermentation in steers grazing dormant blue grama rangeland. Proc. West. Sect. Amer. Soc. Anim. Sci. 37:83.

Caton, J.S., A.S. Freeman, and M.L. Galyean. 1986b. The influence of protein supplementation on rumen and cecal passage rates in steers grazing dormant blue grama rangeland. J. Anim. Sci. 63(Suppl. 1):313.

Caton, J.S., M.L. Galyean, and L.J. Krysl. 1985. The influence of cottonseed meal supplementation on cecal fermentation in sheep fed prairie hay. Proc. West. Sect. Amer. Soc. Anim. Sci. 36:516-519.

DeGregorio, R.M., R.E. Tucker, G.E. Mitchell, Jr., and W.W. Gill. 1982. Carbohydrate fermentation in the large intestine of lambs. J. Anim. Sci. 54:855-862.

Dougherty, R.W.1955. Permanent stomach and intestinal fistulas in ruminants: some modifications and simplifications. Cornell Vet. 45:331-357.

Frank, E.R. 1964. Veterinary surgery. Burgess Publishing Company. Minneapolis, Minn.

Hoover, H.H. 1978. Digestion and absorption in the hind gut of ruminants. J. Anim. Sci. 46:1789-1799.

Krysl, L.J., M.E. Branine, M.L. Galyean, R.E. Estell, and W.C. Hoefler. 1986. Influence of cottonseed meal supplementation on voluntary intake, rumen and cecal fermentation, digesta kinetics and blood insulin and growth hormone in mature ewes fed prairie hay. J. Anim. Sci. 63(Suppl. 1):433.

Phaneuf, L.P. 1957. Studies on the secretory activities of the duodenum, pancreas and cecum of the sheep. Ph.D. Diss. Cornell University, Ithaca, New York.

Ralston, S.L., D.E. Freeman, and C.A. Baile. 1983. Volatile fatty acids and the role of the large intestine in the control of feed intake of ponies. $J$. Anim. Sci. 57:815-825.

Stevens, C.E., R.A. Argenzio, and E.T. Clemens. 1980. Microbial digestion: rumen versus large intestine. p. 685-706. In: Y. Ruckebush and P. Thivend (eds.). Digestive physiology and metabolism in ruminants. AVI Publishing Company, Inc., Westport, Conn.

Ulyatt, M.J., D.W.Dellow, C.S. W. Reid, and T. Bauchop. 1975. Structure and function of the large intestine in ruminants. p. 119-133. In: I.W. McDonald and A.C.I. Warner (eds.). Digestion and metabolism in the ruminant. The University of New England Publishing Unit. Armidale, Australia. 